\title{
Targeting Financial Toxicity in Oncology Specialty Pharmacy at a Large Tertiary Academic Medical Center
}

\author{
Joelle L. Farano, PharmD, MBA, and Huda-Marie Kandah, PharmD, BCPS, CSP
}

\begin{abstract}
BACKGROUND: Patients with cancer often face financial toxicity. They may face financial distress because of high out-of-pocket costs that in turn can result in delays in treatment, treatment abandonment, and higher overall costs of care, all of which can have have a negative effect on patient care. A specialty pharmacy practice model can play a role in decreasing financial toxicity.
\end{abstract}

OBJECTIVE: To evaluate the patient out-of-pocket costs after enrollment in manufacturer patient assistance programs, copay cards, and foundation grants by an oncology specialty pharmacy at University of Chicago Medicine (UCM).

METHODS: For this quality improvement project, a retrospective analysis of prescription claims from January 2017 to June 2017 was performed. The primary outcomes included the number of patients enrolled in manufacturer patient assistance programs, copay cards, and foundation grants, along with the total dollars applied to pharmacy claims. The secondary outcome was the average days to approval of a foundation grant. Inclusion criteria for this quality improvement project included prescriptions filled at UCM Specialty Pharmacy in the 6-month time frame for an oncology indication. Exclusion criteria were prescriptions that were not filled at UCM Specialty Pharmacy due to out-of-network insurance and prescriptions that were part of a patient assistance program where the medication was directly shipped from the manufacturer.

RESULTS: In the 6-month time frame, 75 patients received financial assistance, with a total cost savings of $\$ 314,857$. Financial assistance was most frequently applied to the following medications: peg-filgrastim, dasatinib, abiraterone, filgrastim and filgrastim-sndz, palbociclib, venetoclax, and ruxolitinib. The cost savings of these interventions ranged between $\$ 5$ and $\$ 13,138$ per prescription claim. The average days from date of insurance approval to date of financial grant approval was 1.2 days. CONCLUSIONS: This project demonstrates the importance of an oncology specialty pharmacy team in ensuring timely approval of a foundation grant and reducing financial toxicity, which can play a major role in access to therapy.

J Manag Care Spec Pharm. 2019;25(7):765-69

Copyright @2019, Academy of Managed Care Pharmacy. All rights reserved.

\section{What is already known about this subject}

Since patients diagnosed with cancer are living longer, there has been a shift towards requiring long-term oral anticancer medication and supportive care management.

The costs of oral anticancer and supportive care medications are increasing, leading to financial toxicity for patients.

Financial assistance programs may help decrease high costs and improve medication access.

\section{What this study adds}

This project presents an oncology specialty pharmacy practice model and its role in decreasing financial toxicity.

This project discusses the effect of the use of financial assistance programs, such as copay cards, foundation grants, and manufacturer patient assistance programs.

This project demonstrates how pharmacists and pharmacy technicians can provide ongoing support to patients by ensuring access and affordability with financial assistance programs.

1 here is an emotional, physical, and financial burden that oncology patients are unexpectedly faced with once they are diagnosed with cancer. According to a 2017 study by Narang and Nicholas, who evaluated out-of-pocket costs for patients with cancer, study participants had a mean annual out-of-pocket cost of $\$ 3,737$, which equaled $11.4 \%$ of annual household income. "The term "financial toxicity" has been coined in the literature and first gained traction in 2011. ${ }^{2,3}$ This concept is not fully understood, but Carrera et al. (2018) defined a patient's financial toxicity as the culmination of objective financial burden and subjective financial distress. ${ }^{4}$ Patients with a cancer diagnosis are 2 and a half times more likely than those without cancer to file bankruptcy. ${ }^{5}$

Barriers to accessing OAMs include obtaining prior authorization, lack of time and familiarity, and costs. ${ }^{6}$ In June 2017, The American Society of Clinical Oncology released a statement regarding the affordability of cancer drugs and called for oncology care providers to provide a standardized approach on drug pricing and reimbursement. ${ }^{7}$ Pharmacists are key stakeholders who can decrease the financial toxicity for oncology patients and provide potential solutions to this problem by enrolling patients in financial assistance programs, such as manufacturer patient assistance programs, copay cards, and foundation grants.

The University of Chicago Medicine (UCM) is a large tertiary academic medical center located in Chicago, IL, which includes the Comprehensive Cancer Center. The Comprehensive Care Center was established in 1973 and is a National Cancer Institute-designated cancer center. The UCM Specialty Pharmacy is integrated into the health system, with the provision of medication management services for patients with chronic conditions as its goal. 
The UCM Specialty Pharmacy implemented its oncology specialty pharmacy services in August 2016. This service is supported by 3 pharmacists and 2 ambulatory medication access coordinators. The pharmacists are clinical pharmacy specialists who typically have 1-2 years of residency training and are board certified. These pharmacists are integrated into the outpatient clinics and serve as an extension of the provider team. With each referral, pharmacists perform a clinical review for efficacy, provide medication and disease state education, manage patient adherence, consult with physicians, and provide access to care on a 24/7 basis through a specialty pharmacist on-call program. An ambulatory medication access coordinator is a highly trained certified pharmacy technician who performs benefits investigation, obtains prior authorizations, enrolls patients in financial assistance programs, and performs ongoing refill management. The UCM Specialty Pharmacy is accredited by the Accreditation Commission for Health Care and the Utilization Review Accreditation Commission.

\section{Methods}

\section{Study Design and Data Collection}

This quality improvement project was a retrospective analysis of prescription claims data. The project received a determination of quality improvement status. Since it was not human subject research, this project was not reviewed by the Institutional Review Board.

Data was collected and managed using Research Electronic Data Capture (REDCap; Vanderbilt University, Nashville, TN), an electronic data capture tool hosted at UCM. ${ }^{8}$ REDCap is a secure, web-based application designed to support data capture for research studies and provides (a) an intuitive interface for validated data entry; (b) audit trails for tracking data manipulation and export procedures; (c) automated export procedures for seamless data downloads to common statistical packages; and (5) procedures for importing data from external sources.

Prescription claims data were retrieved from the pharmacy dispensing software ScriptPro (ScriptPro, Mission, KS). The data consisted of patients who filled at least 1 oncology specialty prescription between January 1, 2017, and June 30, 2017. Patient profiles and International Classification of Diseases, Tenth Revision, Clinical Modification (ICD-10-CM) diagnosis codes were reviewed to ensure prescription use for an oncology indication. Relevant ICD-10-CM codes can be found in Table 1. The claims data included primary and secondary payers, which were categorized as third-party payers (Medicare, Medicaid, and commercial) or financial assistance.

Financial assistance plans were further categorized as manufacturer patient assistance programs, foundation grants, and trial and copay cards. Manufacturer patient assistance programs are programs supported by pharmaceutical companies that

\begin{tabular}{l|c}
\hline \multicolumn{1}{c}{ TABLE 1 $\quad \begin{array}{l}\text { List of Oncology ICD-10-CM } \\
\text { Code Categories }\end{array}$} \\
\hline Category & Code \\
\hline Malignant neoplasm of other and unspecified parts of tongue & C02 \\
\hline Malignant neoplasm of other and unspecified parts of mouth & C06 \\
\hline Malignant neuroendocrine tumors & C7A \\
\hline Malignant neoplasm of esophagus & C15 \\
\hline Malignant neoplasm of stomach & $\mathrm{C} 16$ \\
\hline Malignant neoplasm of colon & $\mathrm{C} 18$ \\
\hline Malignant neoplasm of rectosigmoid junction & $\mathrm{C} 19$ \\
\hline Malignant neoplasm of anus and anal canal & $\mathrm{C} 21$ \\
\hline Malignant neoplasm of liver and intrahepatic bile ducts & $\mathrm{C} 22$ \\
\hline Malignant neoplasm of gallbladder & $\mathrm{C} 23$ \\
\hline Malignant neoplasm of body of pancreas & $\mathrm{C} 25$ \\
\hline Malignant neoplasm of bronchus and lung & $\mathrm{C} 34$ \\
\hline Malignant neoplasm of other connective and soft tissue & $\mathrm{C} 49$ \\
\hline Malignant neoplasm of breast & $\mathrm{C} 50$ \\
\hline Malignant neoplasm of unspecified ovary & $\mathrm{C} 56$ \\
\hline Malignant neoplasm of prostate & $\mathrm{C} 61$ \\
\hline Malignant neoplasm of kidney, except renal pelvis & $\mathrm{C} 64$ \\
\hline Malignant neoplasm of brain & $\mathrm{C} 71$ \\
\hline Malignant neoplasm of thyroid gland & $\mathrm{C} 73$ \\
\hline Nonfollicular lymphoma & $\mathrm{C} 83$ \\
\hline Mature T/NK-cell lymphomas & $\mathrm{C} 84$ \\
\hline Other specified and unspecified types of non-Hodgkin lymphoma & $\mathrm{C} 85$ \\
\hline Malignant immunoproliferative diseases and certain other B-cell & $\mathrm{C} 88$ \\
\hline lymphomas & $\mathrm{C} 90$ \\
\hline Multiple myeloma and malignant plasma cell neoplasms & $\mathrm{C} 91$ \\
\hline Mymphoid leukemia & $\mathrm{C} 92$ \\
\hline Benign neuroendocrine tumors & $\mathrm{D} 3 \mathrm{~A}$ \\
\hline Modification. & $\mathrm{D} 47$ \\
\hline CD-10-CMic myeloproliferative disease & \\
\hline
\end{tabular}

provide medications at no cost to financially qualifying patients. Foundation grants are nonprofit organizations that provide financial assistance to fill gaps in coverage and help cover costs for prescription copays, health insurance premiums, and travel costs. Copay cards are used by patients with commercial insurance who have high out-of-pocket costs. The manufacturer patient assistance programs and foundation grants that were assessed included, but were not limited to, the following: Novartis, Johnson and Johnson, Health Well Foundation, Patient Access Network Foundation, and Good Days.

Inclusion criteria for this quality improvement project were prescriptions filled at UCM Specialty Pharmacy in the 6-month time frame for an oncology indication. Prescriptions were excluded if there were no oncology indications, were not filled at UCM Specialty Pharmacy due to out-of-network prescription insurance, and were part of a patient assistance program where the medication was directly shipped from the manufacturer. Prescriptions were also excluded if the financial assistance was 
approved before January 2017, even if benefits were used during this time frame.

\section{Statistical Analysis}

The primary outcomes included the number of patients who were enrolled in financial assistance and the total cost savings in dollars. The secondary outcome was the average days to foundation grant approval. The days to foundation grant approval was defined as the number of days between the date of the paid pharmacy test claim and the date of foundation grant approval. Descriptive analytics were performed. All analyses were performed using STATA software, version 11.0 (StataCorp, College Station, TX).

\section{Results}

There were 233 patients who filled at least 1 specialty pharmacy prescription at UCM Specialty Pharmacy. Of these patients, 75 were enrolled in financial assistance. In the 6-month time frame, the total patient cost savings was $\$ 314,857$. The total number of claims for financial assistance was 153 claims. Financial assistance was most frequently applied to peg-filgrastim, dasatinib, abiraterone, filgrastim and filgrastim-sndz, palbociclib, venetoclax, and ruxolitinib. The cost savings of each intervention ranged from $\$ 5$ to $\$ 13,138$ for the 75 patients who received financial assistance. The highest out-of-pocket cost was $\$ 4,240$. The average days to financial grant approval were 1.2 average days.

\section{Manufacturer Patient Assistance Programs}

The total number of claims for manufacturer patient assistance programs was 25 claims. The total patient cost savings for manufacturer patient assistance programs was $\$ 216,037$. The total patient cost savings per claim was $\$ 8,642$. The total unique patients enrolled in manufacturer patient assistance programs was 14 patients. The total cost savings per unique patient was $\$ 15,431$. The overall mean patient cost savings per claim was $\$ 8,642$ for manufacturer patient assistance programs.

\section{Copay Cards}

The total number of claims for copay cards was 65 claims. The total patient cost savings for copay cards was $\$ 41,416$. The total number of unique patients was 41 patients. The total cost savings per unique patient was $\$ 1,010$. The overall mean cost savings per claim was $\$ 637$ for copay cards, with an average reduction of $88 \%$ on out-of-pocket costs for patients.

\section{Foundation Grants}

The total number of claims for foundation grants was 63 claims. The total patient cost savings for foundation grants was $\$ 57,404$. The total number of unique patients enrolled in copay cards was 20 patients. The total patient cost savings was per unique patient was $\$ 2,870$. The overall mean costs savings per claim was $\$ 911$ for foundation grants, with an average reduction of $99.9 \%$ on out-of-pocket costs for patients.

Table 2 shows the total dollars applied to pharmacy claims by enrollment in manufacturer patient assistance programs, copay cards, and foundation grants.

\section{Discussion}

Financial assistance programs, including copay cards, foundation grants, and manufacturer patient assistance programs, can decrease costs of OAMs. Similar studies have found that these types of financial assistance programs can play a role in reducing out-of-pocket expenses for prescriptions drugs and OAMs. ${ }^{9-12}$ Mitchell et al. (2018) performed a similar study that evaluated the number of oncology patients receiving patient assistance programs for OAMs and the retail value of the assistance. ${ }^{13}$ This study found that $10.6 \%$ of patients obtained a patient assistance program for an oral cancer medication, where our quality improvement project showed $18.6 \%$ of patients received a patient assistance program. The enrollment rate for patient assistance programs is likely an underestimate because patients who received the patient assistance program medication shipment directly from the manufacturer were not included.

The high cost burden of OAMs puts patients at risk for financial toxicity and creates barriers to obtaining life-saving and supportive oncology treatments. Patients who have high out-of-pocket costs are more likely to discontinue cancer therapy. ${ }^{14,15}$ Doshi et al. (2018) found that patient out-of-pocket costs between $\$ 100$ and $\$ 500$ were associated with a 32\% therapy abandonment rate. ${ }^{16}$ This quality improvement project demonstrates how specialty pharmacists and pharmacy technicians integrated within a health system can perform benefits investigations, assess patient out-of-pocket responsibility, and enroll patients in such programs to alleviate the high cost burden of OAMs and prevent therapy abandonment. Pharmacists and technicians provide ongoing support to patients by ensuring access and affordability during the course of therapy.

\section{Limitations}

There are limitations to this quality improvement project. The full scope of UCM Oncology Specialty Pharmacy's effect is limited by the time frame of the quality improvement project, exclusion criteria, and internal barriers. This quality improvement initiative was performed at a large, tertiary academic medical center, with the resources of an integrated, dedicated pharmacy service. The results may not be generalizable to smaller, community hospitals. The 6-month time frame does not account for all patients enrolled in financial assistance since implementation of the specialty pharmacy program. Patients were excluded if they used financial assistance that was awarded before January 2017, which may underrepresent total dollars of financial assistance. 


\section{TABLE 2 Total Dollars Applied to Pharmacy Claims by Enrollment in Manufacturer Patient Assistance} Programs, Copay Cards, and Foundation Grants

\begin{tabular}{|c|c|c|c|c|c|c|c|}
\hline \multicolumn{8}{|c|}{ Manufacturer patient assistance programs } \\
\hline & & Claims, $\mathbf{n}$ & Mean \pm SD, $\$$ & \multicolumn{2}{|c|}{ Median, $\$$} & Range, \$ & Total, \$ \\
\hline \multicolumn{2}{|l|}{ Dasatinib } & 6 & $11,322 \pm 4,448$ & \multicolumn{2}{|c|}{12,414} & $2,244-13,138$ & 67,934 \\
\hline \multicolumn{2}{|l|}{ Abiraterone } & 13 & $9,301 \pm 212$ & \multicolumn{2}{|c|}{9,360} & $8,595-9,360$ & 120,915 \\
\hline \multicolumn{2}{|l|}{ Filagrastim and filagrastim-sndz } & 5 & $3,646 \pm 311$ & \multicolumn{2}{|c|}{3,939} & $2,843-3,570$ & 15,360 \\
\hline \multicolumn{2}{|l|}{ Ribociclib } & 1 & 11,828 & \multicolumn{2}{|c|}{11,828} & 11,828 & 11,828 \\
\hline \multicolumn{2}{|l|}{ Total } & 25 & $8,642 \pm 3,616$ & \multicolumn{2}{|c|}{9,359} & $2,244-11,828$ & 216,037 \\
\hline Copay cards & & & & & & & \\
\hline & Claims, $\mathrm{n}$ & Mean \pm SD & Median, \$ & Range, \$ & Total, \$ & $\begin{array}{c}\text { Average Out- } \\
\text { of-Pocket } \\
\text { Cost Before } \\
\text { Enrollment }\end{array}$ & $\begin{array}{c}\text { Average } \\
\text { Percentage } \\
\text { Saved After } \\
\text { Enrollment }\end{array}$ \\
\hline Peg-filgrastim & 18 & $782 \pm 1,000$ & 125 & $30-3,120$ & 14,076 & 782 & 100 \\
\hline Dasatinib & 3 & $117 \pm 29$ & 101 & $100-151$ & 351 & 117 & 100 \\
\hline Filagrastim and filagrastim-sndz & 7 & $926 \pm 1,401$ & 100 & $50-2,976$ & 6,486 & 926 & 100 \\
\hline Venetoclax & 6 & 76 & 76 & 76 & 456 & 101 & 75 \\
\hline Everolimus & 4 & $239 \pm 279$ & 100 & $100-657$ & 957 & 239 & 100 \\
\hline Afatinib & 4 & 5 & 5 & 5 & 20 & 30 & 17 \\
\hline Lapatinib & 4 & $667 \pm 730$ & 667 & $35-1,304$ & 2,670 & 680 & 99 \\
\hline Imatinib & 3 & $703 \pm 495$ & 700 & $210-1,200$ & 2,110 & 2,186 & 66 \\
\hline Ruxolitinib & 2 & $423 \pm 527$ & 423 & $50-796$ & 846 & 448 & 81 \\
\hline Ibrutinib & 2 & $1,089 \pm 229$ & 1,089 & $926-1,251$ & 2,177 & 1,098 & 99 \\
\hline Palbociclib & 2 & $3,692 \pm 993$ & 3,692 & $2,990-4,395$ & 7,385 & 3,702 & 99 \\
\hline Rucaparib & 2 & $40 \pm 14$ & 40 & $30-50$ & 80 & 40 & 100 \\
\hline Eltrombopag & 2 & 35 & 35 & 35 & 70 & 60 & 58 \\
\hline Enzalutamide & 1 & 231 & 231 & 231 & 231 & 251 & 92 \\
\hline Erlotinib & 1 & 3,326 & 3,326 & 3,326 & 3,326 & 3,351 & 99 \\
\hline Pazopanib & 1 & 75 & 75 & 75 & 75 & 100 & 75 \\
\hline Ribociclib & 1 & 30 & 30 & 30 & 30 & 30 & 100 \\
\hline Midostaurin & 1 & 40 & 40 & 40 & 40 & 50 & 80 \\
\hline Nilotinib & 1 & 30 & 30 & 30 & 30 & 40 & 75 \\
\hline Total & 65 & $637 \pm 1,029$ & 100 & $5-4,395$ & 41,416 & 709 & 88 \\
\hline Foundation grants & & & & & & & \\
\hline Palbociclib & 12 & $1,115 \pm 1,028$ & 552 & $547-3,022$ & 13,379 & 1,115 & 100 \\
\hline Dasatinib & 8 & $352 \pm 282$ & 399 & $60-613$ & 2,816 & 365 & 100 \\
\hline Ruxolitinib & 6 & $978 \pm 987$ & 588 & $555-2,995$ & 5,870 & 978 & 100 \\
\hline Enzalutamide & 6 & $706 \pm 917$ & 500 & $60-2,529$ & 4,235 & 706 & 100 \\
\hline Erlotinib & 5 & 393 & 393 & 393 & 1,965 & 398 & 99 \\
\hline Cabozantinib & 5 & $1,136 \pm 871$ & 756 & $720-2,696$ & 5,683 & 1,136 & 100 \\
\hline Pazopanib & 4 & $1,752 \pm 1,393$ & 1,730 & $547-3,004$ & 7,011 & 1,752 & 100 \\
\hline Vismodegib & 4 & $1,142 \pm 1,187$ & 548 & $548-2,923$ & 4,568 & 1,142 & 100 \\
\hline Venetoclax & 3 & $742 \pm 1,048$ & 154 & $120-1,952$ & 2,226 & 742 & 100 \\
\hline Abiraterone & 3 & $456 \pm 21$ & 468 & $432-468$ & 1,369 & 456 & 100 \\
\hline Sorafenib & 3 & $1,349 \pm 1,609$ & 420 & $420-3,206$ & 4,046 & 1,349 & 100 \\
\hline Filagrastim and filagrastim-sndz & 2 & $1,996 \pm 1,699$ & 1,996 & $794-3,197$ & 3,991 & 1,996 & 100 \\
\hline Ibrutinib & 2 & $123 \pm 88$ & 123 & $60-185$ & 245 & 123 & 100 \\
\hline Total & 63 & $911 \pm 962$ & 549 & $60-3,206$ & 57,404 & 913 & 99.9 \\
\hline
\end{tabular}

The quality improvement project excluded patients with out-of-network insurance and those who received medications directly from the manufacturer as part of patient assistance programs. The UCM Oncology Specialty Pharmacy helps all patients receive financial assistance even if they have out-of- network insurance, so this project underestimated the total cost savings provided to the patient population.

The authors were unable to calculate average percentage saved after enrollment in manufacturer patient assistance programs. Patients are typically enrolled in patient assistance 
programs if they have high copays or are denied coverage by insurance. For these prescriptions, data were not available for what the copay would have been before enrollment in a free drug program. Finally, internal barriers include financial assistance enrollment time frame based on prompt responsiveness from patients.

\section{Conclusions}

$\overline{\text { This quality improvement project revealed how vital an oncol- }}$ ogy specialty pharmacy team is in reducing patient financial burden and improving access to medications. Through financial interventions made by the UCM Oncology Specialty Pharmacy, 1 in 3 patients was enrolled in a financial assistance program, with cost savings ranging from $\$ 5$ to over $\$ 13,000$ per prescription claim. The UCM Oncology Specialty Pharmacy team improved access to copay cards, foundation grants, and patient assistance programs, mitigating financial barriers to treatment initiation and continuation.

\section{Authors}

JOELLE L. FARANO, PharmD, MBA, and HUDA-MARIE KANDAH, PharmD, BCPS, CSP, Department of Pharmacy, University of Chicago Medical Center, Chicago, Illinois.

AUTHOR CORRESPONDENCE: Joelle Farano, PharmD, MBA, UChicago Medicine, 5841 S. Maryland Ave., Chicago, IL 60637. Tel.: 630.290.4480; E-mail:Joelle.Farano@uchospitals.edu.

\section{DISCLOSURES}

No outside funding supported this project. The authors have no conflicts of interest to report.

This project was presented at the Vizient University Health System Consortium Pharmacy Network Resident Poster Session; December 1, 2017; Orlando, FL.

\section{REFERENCES}

1. Narang AK, Nicholas LH. Out-of-pocket spending and financial burden among Medicare beneficiaries with cancer. JAMA Oncol. 2017;3(6):757-65.

2. Carrera PM, Olver I. The financial hazard of personalized medicine and supportive care. Support Care Cancer. 2015;23(12):3399-401.
3. Zhang Y, Hueser HC, Hernandez I. Comparing the approval and coverage decisions of new oncology drugs in the United States and other selected countries. J Manag Care Spec Pharm. 2017;23(2):247-54. Available at: https:// www.jmcp.org/doi/10.18553/jmcp.2017.23.2.247.

4. Carrera PM, Kantarjian HM, Blinder VS. The financial burden and distress of patients with cancer: Understanding and stepping-up action on the financial toxicity of cancer treatment. CA Cancer J Clin. 2018;68(2):153-65.

5. Ramsey S, Blough D, Kirchhoff A, et al. Washington state cancer patients found to be at greater risk for bankruptcy than people without a cancer diagnosis. Health Aff (Millwood). 2013;32(6):1143-52.

6. Bernard DSM, Farr SL, Fang Z. National estimates of out-of-pocket health care expenditure burdens among nonelderly adults with cancer: 2001 to 2008. J Clin Oncol. 2011;29(20):2821-26

7. American Society of Clinical Oncology. American Society of Clinical Oncology position statement on addressing the affordability of cancer drugs. June 1, 2017. Available at: https://www.asco.org/sites/new-www.asco.org/ files/content-files/advocacy-and-policy/documents/2017-ASCO-PositionStatement-Affordability-Cancer-Drugs.pdf. Accessed May 6, 2019

8. Harris PA, Taylor R, Thielke R, Payne J, Gonzalez N, Conde JG. Research electronic data capture (REDCap) — a metadata-driven methodology and workflow process for providing translational research informatics support. J Biomed Inform. 2009;42(2):377-81.

9. Khan G, Karabon P, Lerchenfeldt S. Use of prescription assistance programs after the Affordable Health Care Act. J Manag Care Spec Pharm. 2018;24(3):247-51. Available at: https://www.jmcp.org/doi/full/10.18553/ jmcp.2018.24.3.247.

10. Zullig LL, Wolf S, Vlastelica L, Shankaran V, Zafar SY. The role of patient financial assistance programs in reducing costs for cancer patients. J Manag Care Spec Pharm. 2017;23(4):407-11. Available at: https://www.jmcp.org/ doi/10.18553/jmcp.2017.23.4.407.

11. Felder TM, Lal LS, Bennett CL, Hung F, Franzini L. Cancer patients' use of pharmaceutical patient assistance programs in the outpatient pharmacy at a large tertiary cancer center. Community Oncol. 2011;8(6):279-86.

12. Felder TM, Bennett CL. Can patients afford to be adherent to expensive oral cancer drugs?: unintended consequences of pharmaceutical development. J Oncol Pract. 2013;9(6S):64s-66s.

13. Mitchell A, Muluneh B, Patel R, Basch E. Pharmaceutical assistance programs for cancer patients in the era of orally administered chemotherapeutics. J Oncol Pharm Pract. 2018;24(6):424-32.

14. Kaisaeng N, Harpe SE, Carroll NV. Out-of-pocket costs and oral cancer medication discontinuation in the elderly. J Manag Care Spec Pharm. 2014;20(7):669-75. Available at: https://www.jmcp.org/doi/10.18553/ jmcp.2014.20.7.669.

15. Streeter SB, Schwartzberg L, Husain N, Johnsrud M. Patient and plan characteristics affecting abandonment of oral oncolytic prescriptions. J Oncol Pract. 2011;7(3 Suppl):46s-51s.

16. Doshi JA, Li P, Huo H, Pettit AR, Armstrong KA. Association of patient out-of-pocket costs with prescription abandonment and delay in fills of novel oral anticancer agents. J Clin Oncol. 2018;36(5):476-82. 